\title{
ARQUIVO ESCRILEITURAS: MODOS DE LER E ESCREVER
}

\author{
READING-WRITING FILE: WAYS OF READING AND WRITING
}

\author{
Karen Elisabete Rosa Nodari ${ }^{1}$ \\ Fabiane Olegário ${ }^{2}$ \\ Sandra Mara Corazza ${ }^{3}$
}

\begin{abstract}
Resumo: Este texto toma um dos arquivos produzidos pelo Projeto Escrileituras (2011-2014) tendo em vista mapear as pistas da invenção presente no Roteiro para inventariar procedimentos didáticos de tradução em uma aula que tratava de uma escrita fabuladora. Neste sentido, cria novos procedimentos analíticos com relação ao material arquivado oriundo das universidades parceiras no Projeto: UFRGS (coordenação), UFPel, UFMT e UNIOESTE. Filiado ao campo conceitual operatório deleuziano, postula em termos educacionais, uma didática e um currículo tradutórios, seguindo as indicações de Corazza (2013). Sendo que tem como base os conceitos de diferença pura e de signo, formulado por Deleuze (1988; 2003), o de invenção postulado por Bergson (2006) e o de arquivo proposto por Derrida (2001). Em termos de resultados é possível afirmar a prevalência dos signos das artes nos procedimentos inventivos, a fim propiciar o surgimento de uma escrita potente.
\end{abstract}

Palavras-chaves: Arquivo; signos; invenção.

\begin{abstract}
This paper has taken one of the files produced by the Project Reading-Writing (20112014), aiming at mapping the tracks of invention found in the Guide for an inventory of didactic translation procedures in a class. It designs new analytical procedures in relation to the filed material coming from the Universities that are partners in the Project: UFRGS (coordination), UFPel, UNIOESTE, and UFMT. Following Deleuze's conceptual operational field, it postulates a translative didactics and curriculum in the educational sphere, by following Corazza's guidelines (2013), and based on the concepts of pure difference and sign, as formulated by Deleuze (1988; 2003), invention, by Bergson (2006), and file, as proposed by Derrida (2201). In terms of results, it states the prevalence of the signs of the arts in inventive procedures in order to favor the appearance of a powerful writing.
\end{abstract}

Keywords: File; signs; invention.

\section{Partida}

Partimos do Projeto de Pesquisa, Ensino e Extensão intitulado Escrileituras (2011-2014) que integrou o Programa Observatório da Educação (OBEDUC), em parceria com a Coordenação de Pessoal de Nível Superior (CAPES), Instituto Nacional de Estudos e Pesquisas Educacionais Anísio Teixeira (INEP) e a Secretaria de Educação Continuada, Alfabetização, Diversidade e Inclusão (SECADI) do Ministério da Educação (MEC), no período compreendido entre janeiro de 2011 a dezembro de 2014.

\footnotetext{
${ }^{1}$ Universidade Federal do Rio Grande do Sul, Porto Alegre, RS, Brasil.

${ }^{2}$ Universidade do Vale do Taquari, Lajeado, RS, Brasil.

${ }^{3}$ Universidade Federal do Rio Grande do Sul, Porto Alegre, RS, Brasil. A professora Sandra Mara Corazza nos deixou em 22.01.2021. Amava ensinar e viveu ensinando por frutíferos 40 anos. Nunca deixou de sonhar com uma educação potente capaz de renovar o mundo e o pensamento. Sempre inquieta e combativa às tristezas e aos ressentimentos que minam o campo da educação, Sandra deixa um vasto legado que nos inspira, sendo que a nós cabe agradecer tudo o que produziu em prol da educação, ao mesmo tempo que lastimamos profundamente sua repentina partida.
} 
Nesse período, o Projeto produziu vários arquivos. Como pesquisadoras, tomamos como material teórico-empírico o Roteiro para inventariar procedimentos didáticos de tradução em uma aula. Em tal arquivo encontramos vinte e quatro (24) roteiros que foram respondidos pelos participantes do Projeto, os quais foram matéria da pesquisa de pós-doutoramento intitulada Procedimentos didático-tradutórios sob o signo da invenção desenvolvida no Programa de Pósgraduação em Educação da Universidade Federal do Rio Grande do Sul entre os anos de 2016 e 2017.

Esses roteiros são oriundos dos quatro (04) Núcleos universitários, quais sejam: Universidade Federal do Rio Grande do Sul - UFRGS (Coordenação do Projeto), Universidade Federal de Pelotas - UFPEL (ambas localizadas no Rio Grande do Sul); Universidade Federal do Mato Grosso - UFMT (Mato Grosso) e Universidade Estadual do Oeste do Paraná UNIOESTE (Paraná), que constituíram o Projeto Escrileituras. Tal iniciativa envolveu além dos docentes, alunos da educação básica, graduandos, mestrandos e doutorandos vinculados a Escolas e Universidades públicas, Institutos e Centros Federais, Secretarias Municipais e Estaduais de Educação que promoveram Oficinas de Transcriação.

Ao tomar contato com as obras existentes advindas da Ciência, da Filosofia e da Arte, cada participante pode propor uma Oficina de Transcriação. As Oficinas desenvolvidas durante o Projeto constituíram um espaço de transcriação, onde foi possível experimentar e criar novidades didáticas. Nessa medida, as produções referentes ao Projeto Escrileituras seguiram uma lógica baseada em pressupostos da repetição da diferença (DELEUZE, 1988).

Encerrada a etapa da realização das Oficinas, os participantes foram convidados a responder o Roteiro para inventariar procedimentos didáticos de tradução em uma aula; composto por cinco (05) questões referentes ao seu desenvolvimento teórico-prático didático. A primeira questão do Roteiro solicitava que escrevessem sobre o pensamento de partida que foi traduzido para a elaboração da Oficina, o qual poderia corresponder a um texto, plano argumento, enunciado, discurso, traço, mito, retrato e assim por diante. No segundo tópico, o instrumento pedia a descrição da imagem dogmática do pensamento, da qual o respondente havia partido. Em seguida, era demandado o detalhamento do método de invenção criado que por sua vez colocou um problema, ou um campo problemático. Na penúltima questão, o respondente mostrava como as traduções fizeram a reversão da imagem dogmática do pensamento, anteriormente mencionada. E, por fim, cabia a ele escrever como traduziu e criou outro plano de imanência ou nova imagem de pensamento.

O material recolhido pela pesquisa de pós-doutoramento inscreve-se num dos eixos do Projeto Escrileituras (HEUSER, 2011) denominado biografema. Conceito que tem origem no semiólogo francês Roland Barthes (2005) quer dizer escrever os detalhes de uma vida, as raridades que passam despercebidas ou que ainda não foram significadas e partilhadas no plano cognitivo - contra a cronologia de uma vida e a ilusão biográfica. A fim de transformar detalhes insignificantes (sem significação anterior) em signos de escrita. Utilizar esses signos (aqueles que podem encantar) como disparadores de um texto, ou seja, da escrita de uma vida em experimentação e que, portanto, é produzida na potência da invenção de sentidos

Perseguiu-se, portanto, nos Roteiros para inventariar procedimentos didáticos de tradução em uma aula a invenção de conectores entre ficção e realidade, entre imaginário e história biográfica. Esperava-se que tais dispositivos propiciassem aos seus participantes o ingresso no campo do vivido, das sensações e das invenções; o que implicava, também, a necessária passagem entre o tempo dos estoicos: cronos para aion, a fim de romper com a circularidade do tempo para mergulhar naquele que possibilita algo diferir de si mesmo, ou seja, o tempo da duração. 
Os vinte e quatro (24) roteiros ${ }^{4}$ mostraram como os ministrantes das Oficinas elaboraram e desenvolveram procedimentos didáticos e de que forma esses procedimentos favoreceram o surgimento de uma escrita fabuladora por parte dos seus participantes. Fabulação que não implica em imaginação ou na projeção de um eu, mas uma potência despertada a partir de um encontro com o que dá a pensar, capaz de romper com o pensamento representacional e conduzi-los a habitar outros territórios e tempo, a fim de produzir textos transcriadores.

\section{Arquivo}

No que tange ao arquivo, cabe tomá-lo como uma herança que não se encerra em si mesmo. Nesse entendimento, o legado exclui definitivamente o ponto final e decisivo para as matérias de partida. Trata-se, "portanto, de reinserir tal matéria no jogo ininterrupto e instável do tempo, a fim de que ela não fosse condenada à elisão do esquecimento" (AQUINO, 2014, p. 185).

Impossível para quem recebe esse legado localizar os pontos de origem com precisão, pois assim como a origem "toda a verdade e todo conhecimento não passam de ficções" (CORAZZA; TADEU, 2003, p. 40). Portanto, dilatam-se as suspeitas de que "as coisas no início se encontravam em estado de perfeição; que elas saíram brilhantes das mãos do criador, ou na luz sem sombra da primeira manhã" (FOUCAULT, 2012, p. 59).

Em meio ao tamanho dessa herança, é crucial tomar uma pequena porção, um naco e seguir adiante, na medida em que circunscrevemos um campo problemático. Sendo a sua criação o verdadeiro propulsor do pensamento, pois pensar é levantar problemas. O problema não é a condição de falta e, tampouco carrega a imposição de ser preenchido e solucionado ao contrário, o problema não preexiste a nenhuma resolução dada de antemão, até, porque "as soluções não suprimem os problemas" (DELEUZE, 2011, p. 59).

Isso é o que Deleuze, no capítulo III da obra Diferença e Repetição (1988), denomina de ilusão filosófica, ou seja, conceber os problemas como dados já feitos que desapareceriam na medida que seriam solucionados. A chamada "grotesca imagem da cultura" tão comum nos testes, nos programas líderes de audiência da tv, bem como a Educação possui tal característica.

Portanto, não basta reconhecer a importância do problema para o pensamento, e considerá-lo apenas como um "movimento provisório e contingente, fadado a desaparecer na formação do saber” (DELEUZE, 1988, p. 260), mas afirmá-lo como força potente que ruma à criação de novos problemas. É inegável que os problemas são o que há de mais importante. No entanto, o que interessa é romper com a ilusão natural de decalcar os problemas sobre as proposições do senso comum, da possibilidade lógica de receber uma solução. E, os professores, assim como os alunos, podem formular os próprios problemas.

Nessa direção, consideramos que o arquivo do $(\mathrm{X})$ é crivado de pontos problemáticos, na medida em que se relaciona com a tradição e a tradução. Ainda é preciso dizer que o arquivo é um texto vivo, e que, por tal motivo, constitui modos de pensar e agir. Desse modo, cismamos que não há nenhum arquivo que não tenha sido afetado por borrões e incessantes rasuras tradutórias. Pois, qual seria a função do arquivo senão deixar rastros, verdadeiras materialidades para novas interpretações? Incumbido de tal função, o arquivo demanda daquele que lê e o reescreve condições para reinterpretá-lo no sentido de transformá-lo e fazer repercutir suas matérias.

No processo tradutório, o arquivo submete-se à leitura e novas reescritas do seu conteúdo. Nessa medida, não é à toa que o arquivo viabiliza práticas que movimentam culturas, formas de se relacionar com os objetos e com os seres que fazem parte deste mundo. Sendo assim,

\footnotetext{
${ }^{4}$ Corresponde a cada Núcleo o seguinte número de roteiros: Universidade Federal do Rio Grande do Sul/UFRGS: 04; Universidade Estadual do Oeste do Paraná/UNIOESTE: 09; Universidade Federal de Pelotas/UFPel: 05 e Universidade Federal do Mato Grosso/UFMT: 06.
} 
somos avessas à noção clássica de arquivo, porque o compreendemos como "um instrumento potente da forja histórica, tanto no que se refere à composição de determinado passado, quanto no que diz respeito à invenção do próprio presente" (AQUINO; VAL, 2017, p. 46).

Submetido à recomposição transcriadora, o arquivo não se reconhece como um lugar "de fortalecimento dos mecanismos de memória [...] instituição de guarda dos documentos quanto o conjunto de textos selecionados, organizados e preservados segundo determinada lógica veridictiva" (AQUINO; VAL, 2017, p. 45-46). A suspensão desta imagem assegura uma enigmática presença das matérias arquivadas. Nesse sentido, cabe ao arquivista tomar os arquivos, mesmo porque "o arquivo não fecha jamais" (DERRIDA, 2001, p. 88), sendo que a sua face está sempre voltada para os processos de atualização de seus elementos.

\section{Escrever-e-ler}

Partimos de um texto aberto às interferências do leitor, ou seja, de uma leitura que desfruta da liberdade em produzir sentidos por meio da leitura e da escritura, pois ler está indissociável do escrever (BARTHES, 2012). Tavares (2012), que por sua vez, corrobora a ideia de Barthes, considera a leitura a primeira parte da escrita. E por tais razões, a leitura e a escrita são tomadas como práticas simultâneas - ler e escrever num único gesto - não havendo nessa relação nenhuma primazia, sequer privilégio e tampouco exclusividade de uma sobre a outra. De um modo ou de outro, o que está posto ao escrileitor (escritor e leitor) é a inviabilidade de abdicar da faculdade humana de imaginar. Ademais, "parece que a alegria de ler é o reflexo da alegria de escrever" (BACHELARD, 1993, p. 10).

Ainda na esteira do pensamento barthesiano, ao ler se é convocado a escrever, a fim de ver escorrer a "hemorragia do Imaginário". Nesse caso, podemos afirmar que a escritura é o dedo pousado no imaginário (BARTHES, 2012). Aqui, interessa pensar a imaginação como elemento necessário ao processo tradutório que concretiza através da escritura. $\mathrm{O}$ escritor-eleitor é "deportado sob o registro do Imaginário; toda a sua economia de prazer consiste em cuidar da sua relação dual com o livro (isto é, com a Imagem)" (BARTHES, 2012, p. 37).

A leitura verdadeira, segundo Blanchot (1987) não quer saber o que o autor quis dizer exatamente, e qual é a verdade que o texto anuncia, pois de um modo ou de outro, um texto reivindica uma verdade inventada pelo leitor que atua como coautor de um texto sempre aberto a novas ingerências interpretativas. Polissêmico, o texto se situa em um "jogo interminável de significantes, impossíveis de serem aprisionados numa significação plena" (CORAZZA, 2000, p. 94). Assim, "texto, leitor e escritor tornam-se simulacros, uma vez que estão sempre diferindo de si e do modelo" (HEUSER, 2016, p. 28).

Neste sentido, criamos modos de ler e escrever o arquivo do Projeto (X), pois tomamos "o conhecimento como criação, como invenção" (CORAZZA; TADEU, 2003, p. 47). Modos que se relacionam, primeiramente com o texto de partida (arquivo), para então, reivindicar a produção do texto de chegada; sendo necessário o encadeamento de regras próprias que visam condições de "fazer a língua se mover com palavras cada vez mais sóbrias e uma sintaxe cada vez mais fina" (DELEUZE; PARNET, 1998, p. 72).

Cabe, portanto, a compreensão de que a leitura implica no desejo de querer escrever, e ambas (leitura e escritura), atuam num movimento de troca recíproca, visto que consistem na "força de toda a criação e mesmo toda a procriação" (BARTHES, 2005, p. 15). Um texto, segundo Barthes (2012), só se escreve no momento em que se lê, sendo a escritura uma produção que convoca o corpo todo a trabalhar. Escrever como um trabalho é efetivar a vontade de ler e escrever o arquivo do (X). 


\section{Ler e escrever o arquivo do Escrileituras}

$\mathrm{O}$ arquivo formado pelos materiais produzidos nas oficinas de transcriação passa a ser lido pela óptica barthesiana, uma vez que este compõe uma tessitura, ou seja, os seus textos são como um tecido onde o sujeito pode se desfazer, além de se perseguir a escrita intensiva, como meio de passagem, produtora de múltiplos sentidos. E, com relação ao tempo do ato de criação, sob a perspectiva bergsoniana. De modo que há um tecido da experiência formado por relações intercruzadas, sobrepostas, de acontecimentos que se imbricaram, a partir dos dispositivos acionados pelas diferentes propostas das oficinas. Matéria têxtil formada por linhas contínuas, mas que não deixam de ser compostas por pedaços ligados entre si de maneiras diversas.

As respostas oriundas dos quatro núcleos: UFRGS, UFPel, UNIOESTE e UFMT integrantes do Projeto Escrileituras, obtidas com base no Roteiro para inventariar procedimentos didáticos de tradução em uma aula podem ser analisadas numa triangulação entre algumas de suas questões. Não se trata de reproduzir uma sagrada trindade, ao modo da análise psicanalista - formada pelo pai, mãe e filho, tão combatida por Deleuze e Guattari na obra $O$ anti-Édipo (2011). Mas, de operar com os dados coletados a partir do traçado de um triângulo profano, oriundo de experiências realizadas nesta terra, cujas propostas tinham em comum criar uma nova terra - manifestada pela vitalidade dos textos. De modo que, as condições da invenção que implicaram a realização dos movimentos de preparação, experimentação e de transcriação descritas pelos roteiros serão explicitadas. Uma vez que, como afirma Valéry (1998), é muito diferente ver uma coisa sem o lápis na mão e com o lápis na mão, ou seja, desenhando. No entanto, o fato de se desenhar um triângulo não significa fixálo. Ocorre que mão e visão passam a se intercambiar e se alimentar. É que, "talvez só concebamos bem o que tivermos inventado" (VALÉRY, 1998, p. 203-205).

No entanto, esta operação não consiste em localizar uma de suas pontas para depois ir a outra. Não. Há que se romper com o ordenamento cartesianismo e tomar o triângulo pelo meio. Então, com base nas seguintes questões do instrumento original: 4) Descreva a reversão da Imagem Dogmática do Pensamento (IDP), 5) Plano de Imanência ou Nova Imagem Dogmática do Pensamento ou Nova IDP e 3) Método da invenção constrói-se um triângulo. Sendo que, a partir do encontro entre os seus três vértices é possível seguir as linhas de invenção propostas pelas oficinas desenvolvidas pelos quatro núcleos.

Uma vez que o sentido do percurso do tecido compósito formado pelas linhas de invenção não é fixado de acordo com um princípio de hierarquia ou de sucessão, mas pela sua transformação movente. Pois é sabido que pensar, fabular são forças que liberadas do pensamento representacional, do senso comum e da doxa, podem questionar e experimentar seus próprios limites e traçar intempestivas linhas de fuga - que ligam o que está dentro com o que está fora do triângulo, ou seja, o já pensado com impensado, o velho com o novo, a partir do campo problemático proposto pelo método de invenção desenvolvido por cada ministrante da oficina.

Portanto, somos envolvidos por um tecido triangular de encontros, a fim de desvendar o drama que acompanha todo o logos, como afirmou Deleuze (2006). Distinguir as linhas duras, sedentarizadas e as linhas de fuga. Não se perseguirá os procedimentos que estabilizaram o pensamento dos participantes das oficinas, mas os que os desestabilizaram, de modo a romper com os esquemas da representação. Mas ao contrário, quer-se mapear os diferentes protocolos de invenção propostos para as operações capazes de lidarem com os signos das linhas de fuga e suas duas vertentes: a desejante e a da matéria intensiva. De modo que, a partir de um encontro desestabilizador e intensivo, o pensamento fosse capaz de fabular. Fabulação que não implica na projeção de um eu, mas como diria Schérer (2000) em atingir uma espécie de visão que conduz a devires nascentes. 
Neste sentido, o Núcleo UNIOESTE, formou o seu triângulo com os seguintes elementos: primeiro vértice, a reversão da IDP ocorreu, basicamente, através do trabalho com os signos da arte. Segundo vértice, a nova IDP foi traçada pela decifração de enigmas, proposição de um problema e encontro com os signos da arte e terceiro vértice, o método de invenção, apostou no encontro com os signos e na técnica de brainstorming.

Ou seja, as oficinas apostaram na força, na violência do trabalho com os signos capazes de fazer surgir o pensar uma vez que, isto não se trata de uma possibilidade natural. Os signos foram trabalhados através de obras literárias, leituras dramáticas, poemas, brain storming, jogos que envolveram uma sensibilização do sentir, ou melhor, dos sentidos dos participantes. Portanto, no núcleo UNIOESTE destaca-se uma ênfase no trabalho inventivo proposto pelas diferentes oficinas com os signos da arte. Segundo Deleuze esta superioridade se justifica pela sua imaterialidade de modo acionar, diretamente, o inconsciente dos participantes. O poder dos signos da arte também se justifica pela unidade entre o signo e o sentido. Tendo em vista que, os signos materiais ainda se encontram parcialmente encobertos nos objetos que os carregam. O seu sentido ainda é material. De modo que os participantes das oficinas poderiam sucumbir ao equívoco de confundir o objeto trabalhado com o seu significado. Sendo que a faculdade acionada para sua interpretação era a memória involuntária ou a imaginação.

O Núcleo UFPel formou o seu triângulo utilizando os seguintes elementos: o primeiro vértice, a Reversão da IDP, relacionada à questão IV do Roteiro houve um agenciamento entre os signos da arte com a colocação do corpo em movimento, através de saídas de campo e brincadeiras infantis. O segundo vértice, a Nova IDP ligado a questão V do Roteiro Plano de Imanência ou nova IDP foi formado por necessidades: outros modos de ser professor e uma escrita que não seja cópia, acontecimentos que possibilitaram o rompimento com a temporalidade cronológica e por meio de dispositivos filosóficos e artísticos. E, quanto ao terceiro vértice, o Método da invenção, que corresponde a III questão do Roteiro por um agenciamento entre os conceitos filosóficos, os signos da arte e o corpo em movimento.

A trama inventiva do núcleo UFPel formou-se com as linhas dos conceitos filosóficos, com a colocação do corpo em movimento dos participantes das oficinas e com o encontro com os signos da arte. Uma junção de elementos heterogêneos com o desafio de pô-los a funcionar. Uma vez que é sabido as coisas, o pensamento, só rompem com o estabelecido e ganham vida no meio. No entanto, não se pode esquecer que a origem das ideias não se encontra no sensível, nas matérias, nem nas operações do espírito sobre o sensível, mas no fio condutor formado pelas relações estabelecidas entre os diferentes elementos que compõem o agenciamento. Portanto, o problema deixa de ser o que causou aquela trama, mas o das condições do seu funcionamento. Neste sentido, o núcleo UFPel operou com o movimento de desterritorialização dos corpos, uma forma de inibir a ação dos seus tradicionais esquemas de ação e reação, a fim de que o pensamento dos participantes ao não reconhecerem mais o território em que habitavam, entrassem em relação com o Fora. Uma forma de potencializar o conjunto de afectos que circulou e se transformou naquele território. Produção desejante.

O núcleo da UFMT teve o seu triângulo constituído pelos seguintes componentes: o primeiro vértice que corresponde a questão IV do Roteiro Reversão da IDP se deu através da colocação de situações problemáticas ligadas ao corpo: relação saúde e doença, corpo e alimento, como também num agenciamento com signos da arte. O segundo vértice do triângulo Plano de Imanência ou a Nova IDP que corresponde à questão $\mathrm{V}$ do Roteiro, foi ocupado por diferentes situações que procuravam romper com a imagem dogmática de pensamento e suas diferentes manifestações: seja através da imagem do próprio corpo socialmente imposta e seus modelos de medicalização e sensações que o impedem de fugir do ordinário e criar. Sendo que o terceiro vértice que se liga à questão III do Roteiro Método da invenção foi acionado pela experimentação de um CsO (corpo 
sem órgãos), a fim de esfacelar sua ordenação, inventar novas formas de lidar com ele, aquilo que resta quando se retira qualquer significância e subjetivação, através do trabalho com os signos da arte e com o seu agenciamento a uma situação problemática.

O tecido compósito do núcleo UFMT foi tramado por um conjunto de práticas relacionadas com o corpo. Operações variadas que incluíram movimentos incomuns que o levaram ao seu próprio limite, experiências com diferentes alimentos, a fim de desorganizar o corpo, desmontá-lo, de modo que fosse ocupado somente por matéria intensiva e não estratificada, por onde circulam intensidades e desejos. De modo que dele foi subtraída toda a subjetividade, a fim de transformá-lo num corpo. Artigo indefinido condutor das linhas desejantes a habitar uma nova terra e a produzir novas escritas. Outras formas de travar um encontro com o corpo e pelo corpo/pensamento foi a utilização dos signos da arte. Signos que transbordam o pensar: forças que o impelem o compelem que exigem o uso discordante das faculdades.

E, por último, o núcleo UFRGS constituiu o seu triângulo com os seguintes elementos: o primeiro vértice do triângulo associado à questão IV do Roteiro Reversão da IDP foi preenchido pelo agenciamento entre conceitos filosóficos e a corporificação de um problema, pela reversão dogma cartesiano: penso logo existo através da formulação de problemas, pelo agenciamento entre a proposição de um problema e a potência do encontro, por afecção entre dois tipos de textos. $\mathrm{O}$ segundo vértice do triângulo que corresponde à questão $\mathrm{V}$ do Roteiro, Plano de Imanência ou Nova $I D P$ foi formada através da valoração do movimento do corpo, do corte ao pensamento cartesiano, pela exploração do território do entre e pelo estilhaçar da representação dos sentidos. O terceiro vértice do triângulo, ligado à questão III do Roteiro Método da invenção, foi ocupado pela colocação de problemas que poderiam ou não estar agenciados com os signos da arte.

Os fios da trama inventiva do núcleo UFRGS foram tecidos por vários de seus grupos pela colocação de um problema, a fim de desencadear a gênese da verdade e a produção da verdade pelo pensamento dos integrantes das oficinas. Ou seja, as categorias do verdadeiro e do falso eram validadas pelo próprio problema colocado. E isto acontece quando os oficineiros deixam de elaborá-lo com base nas proposições possíveis e na sua resolubilidade. Deleuze (1988) afirma que os problemas estão em relação com os signos. Lembrando que, posteriormente, em Proust e os signos (2003) a criação, para o filósofo é entendida como a gênese do ato de pensar depende de um encontro violento travado com os signos. Portanto, percebe-se que a grande maioria das oficinas, ao propor um agenciamento entre os signos da arte e a colocação de um problema, potencializou o acionamento do pensamento puro dos participantes. Uma vez que não se cria o novo tendo por base uma boa vontade ou por uma afinidade natural para pensar, mas pela coação realizada pelo encontro dos signos involuntários.

\section{Considerações finais}

Após esta análise da totalidade dos Roteiros didáticos de tradução de uma aula ou oficina dos quatro núcleos, o que dizer sobre as condições da invenção, do campo intensivo criado pelas oficinas de transcriação, dados colhidos com base na triangulação entre as respostas às questões: IV) Reversão da IDP, a V) Nova IDP e a III) Método da Invenção? Todos os quatro núcleos fizeram tentativas de romper com o pensamento representacional e com os seus esquemas de recognição, uma forma de anular nos participantes das oficinas as suas respostas sensório-motoras frente a diferentes situações, a fim de colocá-los em relação com o que dá a pensar e a possibilitar a escrita inventiva. Ou seja, partiu-se da necessidade de acabar com a IDP de modo que a gênese do ato de pensar fosse instaurada. Importante destacar que, todos os núcleos fizeram uso do encontro com os signos da arte. Aqueles que dão a pensar e que são considerados superiores aos demais tipos por serem mais espiritualizados e desmaterializados (DELEUZE, 2003). Violência de encontro a 
impelir os integrantes das oficinas a irem em busca da sua essência: unidade do signo com o seu sentido. Essência que é sempre a diferença. De modo que os seus participantes tomassem contato com o tempo em seu estado puro, ou complicado, tempo inventivo.

Nessa medida, percebemos o privilégio por parte das mais diversas propostas das oficinas em trabalhar com os signos da arte, a fim de que emergisse uma escrita fabuladora. Tendo em vista que o ato da escrita é inseparável de trazer à tona os elementos heterogêneos que a formam, de modo que os participantes fizessem contato com o seu Fora, aquilo que não está nela, mas sem o qual não poderiam criar. Travar um encontro com a essência do signo - a sua importância Deleuze retira de Spinoza, não somente como causa do sentido, mas como causador de efeito. Um efeito supõe corpos que se afetam uns aos outros. De modo que os signos entendido a sua pluralidade, são afetos de passagem, de mudanças de estado registradas por diferenças, variações e devires. Sendo que é do acaso do encontro entre os corpos que emerge o signo, com a potência e alegria para a produção de uma escrita fabuladora.

Tal escolha foi dominante no núcleo UNIOESTE. Quanto ao núcleo UFPel houve uma aposta num agenciamento entre os conceitos filosóficos, a colocação do corpo em movimento e os signos da arte. Já, o núcleo UFMT propôs a criação de um Corpo sem órgãos (CsO), o que implicou também a sua utilização. E, por último, o núcleo UFRGS propôs uma situação problema que envolveu o trabalho com os signos da arte. Interessante observar que, segundo Deleuze (2003), os signos dão o problema e desenvolvem um campo problemático, de modo a tirar as faculdades do seu torpor. Muito embora a decifração dos signos, por si mesma, já coloque um problema, a maioria dos núcleos encontrou diversas formas de dramatizar o seu uso, de criar um campo intensivo: seja através de um agenciamento composto por elementos heterogêneos, incluindo aí os movimentos do corpo, seja pela colocação de um problema específico.

Daí, a necessidade de construir um plano de trabalho para as matérias selecionadas do arquivo que estão em constantes conexões. Um plano capaz de criar novos procedimentos e possibilitar que as matérias extraídas dos arquivos experimentem instigantes aventuras. Por certo, a construção de procedimentos demanda "um pensamento que estaria por ele mesmo obscuro, e que, de direito estaria atravessado por uma espécie de rachadura sem a qual não poderia exercer" (DELEUZE, 2006, p. 125-126), que não encontra outra entrada, senão pela via da leitura e da escritura.

\section{Referências}

AQUINO, Julio Groppa. Da autoridade pedagógica à amizade intelectual: uma plataforma para o éthos docente. 1 ed. São Paulo: Cortez, 2014.

AQUINO, Julio Groppa; VAL, Gisela Maria do. Uma ideia de arquivo: contributos para a pesquisa educacional. Pedagogía y Saberes, Universidad Pedagogica Nacional, Facultad de Educación, Bogotá, Colombia, n. 49, p. 41-53, 2018.

BACHELARD, Gaston. A poética do espaço. Tradução de Antônio de Pádua Danesi. São Paulo: Martins Fontes, 1993.

BARTHES, Roland. A Preparação do romance II: a obra como vontade: notas de curso no Collège de France 1979-1980. Tradução de Leyla Perrone-Moisés. São Paulo: Martins Fontes, 2005.

BARTHES, Roland. O rumor da língua. Tradução de Andréa Stabel. São Paulo: Martins Fontes, 2012.

BLANCHOT, Maurice. O espaço literário. Tradução de Álvaro Cabral. Rio de Janeiro: Rocco, 1987. 
BERGSON, Henry. O pensamento e o movente: ensaios e conferências. São Paulo: Martins Fontes, 2006.

CORAZZA, Sandra Mara. O que faz gaguejar a linguagem da escola. In: ENDIPE (Encontro Nacional de Didática e Prática de Ensino). Linguagens, espaços e tempos no ensinar e aprender. Rio de Janeiro: DP\&A, 2000.

CORAZZA, Sandra Mara. O que se transcria em educação? Porto Alegre: UFRGS, 2013.

CORAZZA, Sandra Mara; TADEU, Tomaz. Composições. Belo Horizonte: Autêntica, 2003.

DELEUZE, Gilles. Diferença e repetição. Tradução de Luiz B. L. Orlandi e Roberto Machado. Rio de Janeiro: Graal, 1988.

DELEUZE, Gilles. Proust e os signos. Tradução de Antônio Piquet e Roberto Machado. Rio de Janeiro: Forense Universitária, 2003.

DELEUZE, Gilles. O método da dramatização. In: DELEUZE, Gilles. A ilha deserta e outros textos. Tradução e organização de Luiz Orlandi. São Paulo: Iluminuras, 2006.

DELEUZE, Gilles. A lógica do sentido. Tradução de Luiz Roberto Salinas Fortes. São Paulo: Perspectiva, 2011.

DELEUZE, Gilles; PARNET, Claire. Diálogos. Tradução de Eloisa Araújo Ribeiro. São Paulo: Editora Escuta, 1998.

DELEUZE, Gilles; GUATTARI, Félix. O anti-Édipo: capitalismo e esquizofrenia. 2. ed. Tradução de Luiz B. L. Orlandi: Editora 34, 2011.

DERRIDA, Jacques. Mal de arquivo: uma impressão freudiana. Tradução de Claudia de Moraes Rego. Rio de Janeiro: Relume Dumará, 2001.

FOUCAULT, Michel. Microfísica do poder. Tradução de Roberto Machado. 25. ed. São Paulo: Graal, 2012.

HEUSER, Ester Maria Dreher. Construcionismo de uma crítica genealógica de escrileituras. In: HEUSER, Ester Maria Dreher. Caderno de notas 8: ética e filosofia política em meio a diferença e ao Escrileituras. Cascavel: EDUNIOESTE, 2016. (p. 25-35)

HEUSER, Ester Maria Dreher. (Org.). Caderno de notas 1: projeto, notas e ressonâncias. Cuiabá, EdUFMT, 2011.

SCHÉRER, René. Homo Tantum. O impessoal uma política. In: ALLIEZ, E. (Org.). Gilles Deleuze: uma vida filosófica. Coordenação de tradução de Ana Lúcia Oliveira. São Paulo: Editora 34, 2000. p. 21-38.

TAVARES, Gonçalo. Breves notas sobre a ciência; breves notas sobre o medo; breves notas sobre as ligações. Lisboa: Relógio D’ Água Editores, 2012. 
VALÉRY, Paul. Introdução ao Método de Leonardo da Vinci. São Paulo: Ed. 34, 1998.

\section{Sobre as autoras}

Karen Elisabete Rosa Nodari. Pedagoga e Doutora em Educação pela Universidade Federal do Rio Grande do Sul (UFRGS). Pós-doutora em Educação pelo Programa de Pós-graduação em Educação PPGEDU/UFRGS. Possui experiência na área da Orientação Educacional, Gestão Escolar e Formação de Professores. Realiza pesquisas com o referencial teórico da Filosofia da Diferença e Filosofia da Educação. Pesquisadora da Rede Escrileituras da Diferença e FilosofiaEducação: REDIF (CNPq/UFRGS) e DIF- Artistagens, Fabulações, Variações (CNPq/UFRGS). E-mail: kernodari@gmai.com.

Fabiane Olegário. Pedagoga pela Universidade do Vale do Taquari (UNIVATES). Mestre em Educação pela Universidade de Santa Cruz do Sul (UNISC) e Doutora em Educação pela Universidade Federal do Rio Grande do Sul (UFRGS). Coordenadora da Pesquisa Procedimentos Didáticos e a reinvenção de arquivos na docência (CNPq/UNIVATES). Coordenadora do Projeto de extensão Pensamento Nômade da Universidade do Vale do Taquari - Univates. Docente no Curso de Pedagogia (UNIVATES). Participa da Rede Escrileituras da Diferença e FilosofiaEducação: REDIF (CNPq/UFRGS) e DIF- Artistagens, Fabulações, Variações (CNPq/UFRGS). E-mail: fabiole@ univates.br.

Sandra Mara Corazza. Licenciada em Filosofia, Mestre e Doutora em Educação pela Universidade Federal do Rio Grande do Sul (UFRGS). Professora Titular da Faculdade de Educação, Departamento de Ensino e Currículo e Programa de Pós-Graduação em Educação. Aposentada em 2019, atua como Professora Convidada no PPGEDU, Universidade Federal do Rio Grande do Sul (UFRGS) Linha de Pesquisa 09; Filosofia da Diferença em Educação. Pesquisadora de Produtividade 1B do CNPQ desde 2002, é Líder dos Grupos de Pesquisa, Diretório do CNPQ/Lattes: 1) DIF - Artistagens, Fabulações e Variações; 2) Rede de Pesquisa Escrileituras da Diferença em Filosofia-Educação (in memoriam). 